\title{
AMÉRICA LATINA, 100 ANOS DA REVOLUÇÃO RUSSA, EDUCAÇÃO E ENSINO
}

\author{
AMÉRICA LATINA, 100 AÑOS DE LA REVOLUCIÓN RUSA, EDUCACIÓN Y \\ ENSEÑANZA
}

\section{LATIN AMERICA, 100 YEARS OF THE RUSSIAN REVOLUTION, EDUCATION AND TEACHING}

\author{
André Paulo Castanha ${ }^{1}$ \\ João Carlos da Silva ${ }^{2}$
}

Prezados leitores, com satisfação apresentamos o V. 9, N. 3, referente a setembro e dezembro de 2017, da Revista Germinal. Nesse número a temática central é: América Latina, 100 anos da Revolução Russa, Educação e Ensino.

Em grande parte a realidade vivida pela América Latina nos últimos 100 anos tem sido marcada pela Revolução Russa, ainda que não apareça de forma muito explícita. Sem dúvida, trata-se de um acontecimento central para a história da humanidade. Daí, por um lado, se a preocupação dos capitalistas e seus ideólogos tem sido a de combatê-la, denegri-la, condená-la ao esquecimento e deletá-la da história, para os trabalhadores representa um marco fundamental na construção de uma nova humanidade, um passo para o reino da liberdade.

Com esse significado, fazemos deste número uma homenagem à Revolução Russa, com a esperança de que possa inspirar muitas e boas lutas pela superação do capitalismo em favor da humanização. Esta edição está composta pelas seguintes seções: debates, artigos, entrevistas, texto clássico, resenhas e resumos.

Quando nos foi solicitado a apresentação e organização desse número, imediatamente nos veio à mente o texto/discurso de Lenin ${ }^{3}$ aos jovens russos em 1920. Nesse discurso, Lenin indagou aos jovens que queriam se engajar no movimento revolucionário, sobre o que aprender e a resposta central foi aprender o Comunismo. Daí surgiram as perguntas: "Que necessitamos para aprender o comunismo? Que necessitamos escolher, entre a soma de conhecimentos gerais, para adquirir a ciência do comunismo?” (2002, p. 10-11).

Lenin deixou claro que não era uma tarefa fácil, unilateral, com isso deixou implícito a pergunta: qual comunismo? O conhecimento dos manuais, folhetos e obras comunistas? Segundo ele, "estas pessoas, depois de ter lido muito e aprendido o que se expõe nos livros e folhetos comunistas, seriam 
incapazes de coordenar todos estes conhecimentos e agir como exige realmente o comunismo". Isso porque, no entendimento de Lenin, a herança da "velha sociedade capitalista é o completo divórcio entre o livro e a vida prática". Assim, "seria um grande erro limitar-se a assimilar simplesmente o que dizem os livros do comunismo". É preciso que esse conhecimento esteja ligado ao "nosso trabalho diário em todos os terrenos" (2002, p. 11). Nesse sentido Lenin nos ensina:

Sem trabalho, sem luta, o conhecimento livresco do comunismo, adquirido em folhetos e obras comunistas, não tem absolutamente nenhum valor, uma vez que não faria mais que continuar o antigo divórcio entre a teoria e a prática, esse mesmo divórcio que constituía o mais repugnante traço da velha sociedade burguesa (2002, p. 11-2).

A partir dessa provocação que Lenin nos faz, passamos a apresentar o conjunto de textos que compõem esse número, os quais, certamente nos ajudarão a conhecer melhor os embates travados na América Latina nesses últimos 100 anos e fortalecerão nossas ações cotidianas em defesa de uma sociedade socialista.

A seção Debates está composta por quatro textos que discutem a situação de alguns países da América Latina.

O primeiro texto, Crise Mundial, Ofensiva Capitalista e o Papel dos Povos da Nossa América, de Julio C. Gambina, analisa a situação global da crise capitalista e a ofensiva do capital contra os trabalhadores na América Latina, com destaque para a Venezuela, Bolívia e Equador e Cuba. Também trata da situação do Brasil, Uruguai e Argentina. Já no texto: Ebolição Frente ao Ajuste na Argentina: a cleptocracia desafiada, Claudio Katz mostra como na Argentina, cresce a resistência contra as reformas promovidas pelo governo Macri. Nesses embates se destacam os professores como protagonistas e certa complacência das lideranças sindicais frente às reformas.

Ramón Casanova, no texto: A Gramática do Chavismo: entre a Pulsão Socialista e o Redentorismo Popular - notas de investigação, faz uma interpretação sociológica do contexto atual da Venezuela considerando os embates entre os sujeitos coletivos que mobilizam, os imaginários sociais e as tradições intelectuais, tomando como uma expressão da crise histórica do padrão de modernização capitalista ligado as lógicas sociais que produzem a economia rentista do petróleo, base da economia venezuelana.

Na sequência, Paulino José Orso, no texto: América Latina à Espera pelo Grito dos Livres, analisa, numa perspectiva histórica, como essa porção do continente americano, primeiramente submetida ao domínio europeu e, posteriormente, estadunidense, sob o lema: “América para os americanos", passou a ser controlada pela política do Big Stick (Grande Porrete), que patrocina golpes, implanta ditaduras e planta governos subservientes a seus interesses. A análise visa esclarecer os desafios que estão colocados para os trabalhadores Latino-americanos, passo necessário na luta pela libertação e emancipação.

A seção Artigos está composta por dezenove textos que tratam de questões ligadas a revolução, economia, política, educação e ensino nos últimos cem anos de história.

No artigo: Fidel Castro: Algumas de suas Contribuições Teórico-Práticas para as Inconclusas Lutas pela Emancipação de Nossa América, Luis Suárez Salazar mostra os diversos 
compromissos assumidos por Fidel Castro com as lutas pela emancipação da América Latina e do Caribe. Como líder histórico da Revolução cubana, convocou à "unidade anti-imperialista" e expressou sua utopia de que todos os estados do continente pudessem se integrar económica e politicamente como uma condição necessária, mas não suficiente para que suas nações e seus povos pudessem transformar em realidade os ideais dos fundadores das lutas pela independência do colonialismo ibérico e norte americano.

Agatha Justen Gonçalves Ribeiro e Claudio Roberto Marques Gurgel, no artigo: Mecanismos Institucionais de Participação Social e Barreiras Estruturais: o caso do Equador, procura expor a proposta revolucionária em curso no Equador e examiná-la em face do modo de produção capitalista que subsiste nesse país, indagando sobre o que se pode ter como expectativa e que avanços essa experiência pode trazer. Já em, Que Mudanças Podem Ocorrer com a Implementação do Acordo de Paz na Colômbia? Carolina Jiménez Martín, propõe em discussão uma série de questões que buscam contribuir para a análise das transformações estruturais que podem ocorrer a partir da assinatura do Acordo de Paz entre os guerrilheiros das FARC-EP e o governo colombiano.

Guadelupe Teresinha Bertussi, no texto: Uma Reforma Jurídica e Administrativa da Educação: o caso do México analisa a reforma estrutural educativa neoliberal implantada pelo governo mexicano que se caracteriza pela ausência do modelo educativo. Apresenta as pressões sociais contra estas medidas e enfatiza, que a frágil hegemonia e legitimidade do atual governo, põe em dúvida a continuidade do seu partido e da própria reforma no próximo período presidencial, a partir de dezembro de 2018 . Na sequência, Patricia Simone Roesler, no artigo: A Educação Paraguaia: Quatro Marcos Históricos Decisivos, registra a trajetória da educação do Paraguai destacando seus principais marcos históricos e as bases da organização da educação atual.

No texto: Contribuições de José Carlos Mariátegui às Análises em Política Educacional, Gilcilene de Oliveira Damasceno Barão e Leandro Sartori Gonçalves, apresentam o estado da arte dos aportes teórico-metodológico que embasam os estudos das políticas educacionais. Após isso, inventariam alguns destes fundamentos teórico-metodológicos no contexto latino-americano, dialogando com a produção do peruano José Carlos Mariátegui.

Julio Carlos Figueiredo, no artigo Impeachment no Brasil: o Governo Temer e a Privatização nas Universidades Públicas Brasileiras, mostra o avanço das privatizações nas universidades públicas brasileiras e avalia as principais iniciativas do governo Michel Temer que confluem nesta direção. As análises indicam um processo em curso, onde o ensino público, em particular, o ensino superior, está submetido a uma dupla apropriação: enquanto mercadoria e como setor público a serviço da acumulação privada.

No texto: Coup D'état e Exclusivismo Político-Educacional: uma Análise da Medida Provisória 746/2016, Marcelo Lira Silva mostra como a constituição do capitalismo brasileiro, dependente e subordinado ao epicentro do capitalismo mundial produziu uma classe dominante caracterizada pelo exclusivismo político; e, consequentemente, pela não admissão de qualquer tipo de participação e representatividade das classes trabalhadoras e demais classes subalternas nos processos 
decisórios do país. Essa característica viabilizou as condições objetivas e subjetivas para os constantes golpes de estado no país, atendendo aos interesses dos detentores do capital.

Renan dos Santos Sperandio e Ana Carolina Henriques do Nascimento Muniz, no artigo Paradigmas Positivistas nas Reformas Educacionais do (Des)Governo Temer: do Escola sem Partido ao Novo Ensino Médio, contextualizam a crise política atual no Brasil e analisam o movimento Escola "sem" Partido e a Reforma do Ensino Médio do governo Temer. Os autores enfatizam que tanto o projeto de reforma do Ensino Médio, quando o programa "Escola sem Partido" partem de análises rasas da realidade, que escamoteiam a verdade, confundem a comunidade escolar, desfocam o real problema da educação básica, principalmente do Ensino Médio.

O texto, Trabalho e Produção Associada em Comunidades Tradicionais: Experiências de Existências e Resistências, de autoria de Ana Paula Bistaffa de Monlevade, Edson Caetano tem como foco central a análise das experiências de diversas comunidades tradicionais presentes no estado do Mato Grosso. Os autores trazem exemplos de formas autogestionárias, coletivas, solidárias e cooperativas de produção da existência, em que trabalhadoras e trabalhadores buscam resistir ao individualismo, ao mercado, à competição e à maximização dos lucros, demonstrando que possuem uma específica concepção de mundo e de trabalho.

No texto: A Profissionalização Imposta por Decreto: Notas sobre a Reformulação Neoliberal na Educação dos Trabalhadores Brasileiros, José Deribaldo dos Santos debate as relações entre os decretos $\mathrm{n}^{\circ} 2.208 / 97$ e o decreto $\mathrm{n}^{\circ}$ 5.154/04, que tratam da modalidade de ensino profissionalizante no Brasil a partir de uma perspectiva crítica marxista.

Luciano Ferreira Rodrigues Filho, no texto, O Fascismo Explicado pelos Filmes “a Árvore dos Tamancos", “Germinal” e "1900”: Ascensão Ideológica no Brasil, tem como foco a ascensão fascista no início século XX, como movimento de estruturação do capitalismo. Nesse sentido, fez um paralelo com o movimento social e político dos filmes para evidenciar a crescente ideologia fascista no Brasil neste início de século XXI.

Joana A. Coutinho, no texto A Educação como Mercadoria: Formar para a Subserviência, analisa o processo de mercantilização da educação sob a égide do neoliberalismo, buscando compreender o desmonte da educação pública. Em sendo tratada como uma mercadoria, a educação tem como função central apenas preparar os jovens para o tal "mercado de trabalho e não para a humanização.

O artigo: Lênin e Che Guevara, de autoria de Luiz Bernardo Pericás abre os textos que abordam mais especificamente a temática da Revolução Russa. Nele, o autor discute as ideias e leituras de Lenin e Che Guevara sobre o marxismo, à revolução socialista e aos caminhos para o desenvolvimento econômico.

O artigo Apontamentos sobre o Legado da Revolução Russa de 1917, de Marco Antonio de Oliveira Gomes, Marilsa Miranda de Souza e Márcio Marinho Martins retoma o legado da Revolução Russa como um marco significativo na luta dos trabalhadores de todo o mundo. Nesse sentido, evidenciam uma série de conquistas que contribuíram para a superação de práticas de exploração dos trabalhadores. 
Elza Margarida de Mendonça Peixoto, no texto: 100 Anos da Revolução Russa: as Lições da Política para a Educação - Notas de estudos de obras de Lenin e Krupskaya, procura evidenciar a demanda pela educação nos processos revolucionários, para o convencimento da justeza da revolução e para a formação dos proletariados em dirigentes. Segundo a autora, a retomada do pensamento de Lenin e Krupskaya, não se trata de um “parodiar” a Revolução Russa como um tipo ideal a ser seguido, nem de criticá-la por não ter atingido um suposto tipo ideal do que deveria ter sido, mas sim para "glorificar as novas lutas", para "descobrir o espírito da revolução", para "exaltar na fantasia as missões recebidas". Cabe a nós reconstruirmos espaços coletivos e levar a luta adiante.

A revolução Russa também é objeto de análise de José Claudinei Lombardi. No texto: A Revolução Russa e os Desafios À Pedagogia Histórico-Crítica, o autor traça as linhas gerais da educação nas condições históricas em que se deu a Revolução Russa e procura evidenciar possíveis contribuições da educação na Rússia revolucionária, para o processo de construção da Pedagogia Histórico-Crítica.

Vanderlei Amboni, no artigo, O Trabalho como Referência Educacional na Formação do Homem Soviético, analisa a ação pedagógica desenvolvida no período revolucionário da URSS para forjar o homem soviético, cujo fundamento era o trabalho na busca da omnilateralidade do homem. O autor concluí que a escola criada pelo trabalho na Rússia revolucionária tinha, portanto, uma singularidade nova e uma urgência educacional, cuja premissa é a formação de um novo homem pelo trabalho e uma nova moral social: a comunista.

O artigo, A Pedagogia de Makarenko: Aproximações de um Modelo Socioeducativo na Revolução Russa, de Walace Roza Pinel e Erlando da Silva Reses fecha a seção. No texto, os autores destacam o relevante trabalho do educador socialista Anton Makarenko na luta em favor da educação, como projeto social dirigida aos excluídos e analisam sua influência no Brasil, junto aos Movimentos Sociais e Populares, na formação sindical e nas Comunidades Eclesiais de Base vinculados às tendências progressistas da Igreja Católica.

A seção Entrevista traz num só texto, os depoimentos Paola Claudia Carolina Estrada Camargo, Jorge Giordani e João Pedro Stedile. Os entrevistados procuram refletir sobre a ação dos movimentos sociais no contexto atual. Paola Claudia Carolina Estrada Camargo, analisa O Brasil no contexto das mudanças na América Latina e no império, Jorge Giordani trata da Venezuela e desafios do tempo presente, e João Pedro Stedile, faz uma Análise da situação política e dos movimentos populares da América Latina.

Na seção Texto Clássico, republicamos o texto: Dialética da Dependência Ruy Mauro Marini A primeira edição deste Ensaio foi escrita em 1973. No mesmo ano o autor escreveu um texto complementar, à guisa de post-scriptum, segundo ele, "para esclarecer algumas questões e desfazer certos equívocos que o texto tem suscitado". Esta versão conta com a tradução de Marcelo Carcanholo, da Universidade Federal de Uberlândia e o Post-scriptum foi traduzido por Carlos Eduardo Martins, Universidade Estácio de Sá. 
A seção Resenha traz duas análises. Maria de Fátima Rodrigues Pereira interpretou a obra, Política, Estado e ideologia na trama conjuntural, de Mauro Iasi e Adriana Almeida Sales de Melo fez a leitura da obra Introdução ao fascismo de Leandro Konder.

Na seção Teses e Dissertações - Resumos são apresentadas seis produções: Contribuição à Crítica da Base Nacional Comum Curricular - a máscara do conformismo na educação do Banco Mundial, de autoria de Carolina Ramos Heleno; Ditadura, Agricultura e Educação: a ESALQ/USP e a Modernização Conservadora do Campo Brasileiro (1964 a 1985), de Rodrigo Sarruge Molina; Marxismo e Educação no Brasil (1922-1935): o discurso do PCB e de seus intelectuais de Aparecida Favoreto; Os Fundamentos Econômicos Políticos da Dependência Brasileira e as suas Contribuições à Apreensão da “Questão Social”, escrita por Pedro Rafael Costa Silva; A reforma educacional paraguaia de 1994, defendida por Patricia Simone Roesler; Educação do Campo e Ensaios da Escola do Trabalho: a materialização do trabalho como princípio educativo na escola itinerante do MST Paraná, de autoria de Valter de Jesus Leite.

Ao finalizarmos esta apresentação, queremos chamar a atenção dos leitores para a qualidade dos textos aqui publicados. Estamos cientes de que a leitura deles vai ampliar, consideravelmente nosso entendimento sobre a sociedade atual e sobre o socialismo. Que as análises aqui disponibilizadas possam qualificar nossa práxis cotidiana, na luta por uma outra sociedade.

\footnotetext{
Notas:

1 Professor do Colegiado de Pedagogia e do Programa de Mestrado em Educação da UNIOESTE - Campus de Francisco Beltrão. Pós-Doutor em Filosofia e História da Educação pela UNICAMP. E-mail: andrecastanha66@gmail.com

2 Professor dos cursos de Pedagogia e do Mestrado em Educação da Unioeste. Dr. pela Unicamp, integrante do grupo de pesquisa Histedopr. E-mail: joao.silva@unioeste.br

${ }^{3}$ LENIN. Tarefas da juventude na construção do socialismo. In: As tarefas revolucionárias da juventude. 3 ed. São Paulo: Expressão Popular, 2002, p. 9-32. (Cadernos de Expressão Popular).
} 